CAMARGO, Fábio Figueiredo. A vida Suspensa. Belo Horizonte: Scriptum, 2014.

\title{
A Vida Suspensa no tempo/espaço ficcionais
}

\author{
Maiane Pires Tigre 1 \\ Bárbara Luiza Menezes Lago 2
}

A Vida Suspensa (2014) exprime a nudez da escrita de Fábio Figueiredo Camargo, escritor e professor do Instituto de Letras e Linguística da Universidade Federal de Uberlândia (UFU), além de professor colaborador do Programa de Pós-graduação da Unimontes. Originalmente concebida após ter participado da "Oficina Surtos de Inverno", ministrada por Gilberto Noll, em 2007, na cidade de Diamantina, a obra foi retocada "por olhos dos mais variados tamanhos, cores e formas", resultando no encadeamento de 26 contos que colocam a vida humana em suspensão (CAMARGO, 2014, p. 07).

Em seus textos, Camargo (2014) adota a estética literária contemporânea, caracterizada pela ruptura ao conto moderno, através da qual introduz a retórica pessimista de oposição aos modelos totalizadores empregados. Demarcados por seu caráter fragmentário, tais contos refazem uma crítica à modernidade ao desentalhar as formas e os conteúdos das narrativas mestras, inserindo-se no quadro teórico do conto pós-moderno.

A representação da realidade amalgama-se de tal modo ao jogo de ilusões, que chega a desencadear no leitor chaves interpretativas próximas do inverossímil e improvável, prescindindo, algumas vezes, do pacto de leitura estabelecido. Apesar disso, os contos estão

\footnotetext{
${ }^{1}$ Mestranda em Letras: Linguagens e Representações/UESC. Bolsista Capes. Pesquisadora do grupo de pesquisa "África/Brasil: literaturas em português - saberes e sentidos de resistência cultural” coordenado pela Profa. Dra. Inara de Oliveira Rodrigues E-mail: maiane.tigre@ hotmail.com.

${ }^{2}$ Acadêmica do curso de Letras - Inglês da Universidade Estadual de Santa Cruz. Pesquisadora do Grupo de pesquisa "África/Brasil: literaturas em português - saberes e sentidos de resistência cultural" coordenado pela Profa. Dra. Inara de Oliveira Rodrigues lotada no Departamento de Letras e Artes e do Mestrado em Letras: Linguagens e Representações da UESC.E-mail: lala.lago@ hotmail.com
} 
concatenados por fios de sentidos que imprimem à obra o poder de reconversão, em outras palavras, os variados cenários e enredos que parecem anunciar outros sentidos, convergem para a análise dos impasses das personagens diante de situações decisivas.

Dessa forma, concilia o inconciliável, isto é, as forças antagônicas que suspendem os limites da vida, e manifestam o veio da paixão associado à irracionalidade de atos criminosos. Camargo ficcionaliza personagens envolvidas em tramas cotidianas que escamoteiam o trágico e desocultam as verdades pessoais de cada uma, por essa razão, tais contos são capazes de prender o fôlego do leitor do início ao fim.

A linguagem de Camargo, embora marcada por níveis de subjetividade, graças às relações amorosas descritas, choca pela força da agressividade evidenciada na construção de imagens que desfiguram a natureza humana. A violência explicitada nos contos fotografa a crueza e barbárie camuflada nas relações humanas, muitas vezes irrepresentáveis na ficção, mas ilustrada com maestria pelo autor. As personagens perfilam sobre planos de realidade distintos, evocando nos leitores secretas identificações; flagradas no ápice do descontrole de suas ações, essas personagens se transformam em autores de assassinatos, pedofilia, canibalismo, entre outros.

Através de uma linguagem enxuta, o escritor explora a fundo o recurso da descrição, inserindo o leitor na cena narrada, mediante o exercício de transposição do imaginário para participação em episódios reais. $\mathrm{O}$ autor aglutina as ações dos contos de modo uniforme, de maneira que parecem pertencer a um bloco textual organizado, de súbito, porém, a narrativa é desestabilizada, desestruturada por um desfecho surpreendente e inesperado. $\mathrm{O}$ arranjo das ações anteriormente justapostas é desarrumado, e a narrativa agora apresenta um fim imprevisível, procedimento perceptível nos contos "Produção", "Mãos”, “A primeira vez”, "A troca" e "Adiamento".

Em “A primeira vez", o narrador investe nos efeitos sensoriais da linguagem sobre o leitor, conferindo maior poeticidade e beleza estética ao enredo funesto. O conto, mais uma vez, trabalha com o elemento surpresa, contudo, a diferença incide sobre o fato de que o título alude a um evento auspicioso narrado em prosa poética, o que contrasta com a parte final: uma personagem caindo de um lugar alto em direção ao chão. Esses e outros contos fazem uma releitura dos fatos trágicos, de sorte que podem ser lidos e auscultados de baixo para 
cima, permitindo uma possível inversão da realidade, bem como da disposição do conteúdo narrado.

Arriscar-se à leitura de A Vida Suspensa (2014) é admitir a liberdade da escrita viva, imagética, desencarnada de regras e que, uma vez suspensos os limites da linguagem, furta-se do"mundo mesquinho e real para outro menos sólido, porque virtual, mas, ao mesmo tempo, mais próximo do que você gostaria", trecho extraído do conto "Espaço" (CAMARGO, 2014, p. 88). Esse conto refere-se à escrita como sintomática de uma voz e som separados do corpo, porque inscritos no papel, o texto narrado, então, converte-se na testemunha do pacto visceral entre autor e leitor, auxiliando na conciliação das partes envolvidas.

O contrato da leitura consolida-se à medida que os papéis do texto, autor e leitor se tornam inconfundíveis e constituem-se no caráter ineludível do pacto ficcional, pois "ler é compactuar com essa doação ilimitada que é escrever" (CAMARGO, 2014, p. 88). O leitor que se transforma após a leitura, o texto que deseja ser lido e, por fim, o autor que almeja ser acessado através do seu corpo textual são algumas evidências desse pacto, afinal “o texto está na página à espera o outro. O leitor, meu espelho [...] me lê em partes assim como meu texto só o suporta pelos fragmentos [...] cada parte do meu texto, cada letra é mais do que meu corpo ao mesmo tempo em que é parte dele [...]. Aquele que lê sente-se transmutado"(CAMARGO, 2014, p. 88).

Algumas características da poética da pós-modernidade encontram-se embutidas na verve da produção literária de Camargo, são elas "descontinuidade, desmembramento, deslocamento, descentralização, indeterminação e antitotalização" (HUTCHEON, 1991, p. 19). Diante disso, é possível comprovar nos contos de A Vida Suspensa (2014) a existência de narrativas descontínuas, descentralizadas, desmembradas e antitotalizadoras, tal como se dá em "Desvario", "Desgosto" e "Na saída do cinema". Nesses contos são apresentadas três perspectivas distintas das personagens, a saber, do namorado, da namorada e da vítima da agressão respectivamente, ou seja, três narradores que se posicionam de forma paradoxal em relação ao mesmo fato.

De modo particular, no conto "Escama", observa-se uma narrativa indisciplinada, em relação aos esquemas textuais consagrados, verificável a partir da supressão dos sinais de pontuação, por exemplo. Tal atitude, compromete e ao mesmo tempo amplifica as possibi- 
dades interpretativas do texto: "Mornas macias marrons melancólicas me aguardavam em cima da cama perto da mala das meias mescladas mudas marcadas por muito uso em invernos" (CAMARGO, 2014, p. 36 ).

Com efeito, o conto pós-moderno é definido como: "aquele texto que põe em evidência, que problematiza, desestrutura e discute, dentro de uma articulação formal, estética e paródica o próprio conto moderno, uma relação de apropriação, imitação, assassinato e abandono de seu predecessor" (OGLIARI, 2012, p. 10). Nessa ótica, os contos de Camargo desestruturam o próprio fazer literário, quando refletem sobre questões proibidas e de um modo incomum. Ao apropiar-se da estética do banal e paródica, tendo como referência as atitudes humanas, o narrador banaliza parodicamente o outro, como no conto "A troca", em que o namorado come o pênis do parceiro assado, na esperança de que o outro viva nele.

Os contos de Camargo estão atravessados por elementos teóricos da estética hiperrealista, corrente que propõe o detalhamento das formas na pintura, oriunda do realismo no século XIX. Consequentemente, o livro apresenta uma abordagem onírica da vida em sociedade, incorporando estratégias do insólito para abordar temas do cotidiano sem o manto do julgamento. Dessa forma, os contos de A Vida Suspensa (2014) "através de um discurso metafórico e de lógica onírica, pretendem, crítica e mascaradamente, dramatizar situações passíveis de censura" (SANTIAGO, 1982, p. 52).

Camargo dá ênfase à ação das personagens em sua narrativa, costurando o enredo de modo a preencher os vazios da ficção. Assim, o leitor é, intencionalmente, submetido a uma parada, severa interrupção, instante em que a vida e, por conseguinte, o tempo se encontra suspenso, obrigando leitor e personagem a esboçarem reações que os permitam escapar do destino inexorável.

Ao que parece, a obra de Camargo, em síntese, revisita o espaço da produção literária, transitando por dentro e por fora do texto no exercício da metalinguagem, assunto que abre e encerra o livro, a partir de um processo cíclico. Em "Produção", o autor reflete sobre o ofício de escrever examinando o tecido textual que, por um lado, obedecem aos limites do papel, pois nesse aspecto "nada mais há a fazer. O texto está morto", e por outro, transgride-os a partir de narrativas desobedientes. O conto "Espaço" é um exemplo disso, para o qual inexistem limites, pois estes já foram superados durante a escrita de A Vida Suspensa (CAMARGO, 2014, p. 13). 
Em resumo, o texto não pode estar morto, porquanto o leitor está vivo, em função da leitura que realiza, e o autor adquire vida cada vez que o seu texto é lido. Nesse caso, há ainda muito a fazer pela escrita, Camargo dá a receita: "Ser livre nesse espaço sem limite algum além do pedaço de papel que tenho em mãos agora. Você lê em que papel?, Qual o limite? Qual a leitura?” (CAMARGO, 2014, p. 88).

Assim, a leitura dessa obra interessa a todos aqueles quer seja na academia, especialistas, estudantes, ou fora dela, leitores em geral que estudam o texto literário, pois esta produção se diferencia das outras coletâneas de contos pelo alto grau de originalidade no tratamento dado aos temas. Marcado com as pinceladas do hiperrealismo, em um estilo que lembra a aspereza de Rubem Fonseca, a representação da realidade destaca-se pela presença do insólito, rompendo a lógica das ações humanas no tempo e espaços ficcionais.

\section{Referências}

HUTCHEON, Linda. Poética do pós-modernismo: história, teoria e ficção. Tradução Ricardo cruz. Rio de janeiro: Imago, 1991.

OGLIARI, Ítalo. A poética do conto pós-moderno e a situação do gênero no Brasil. Rio de Janeiro: 7letras, 2012.

SANTIAGO, Silviano. Vale quanto pesa. Rio de Janeiro: Paz e Terra, 1982. 